\title{
Competencias de lectura y escritura en música. Una propuesta para su asimilación en el currículo escolar*
}

\author{
RUTH NAYIBE CÁRDENAS SOLER \\ Universidad Pedagógica y Tecnológica de Colombia, Colombia \\ ruthnayibecardenas@gmail.com \\ JUAN DIEGO MARTÍNEZ ÁLVAREZ*** \\ Universidad Pedagógica y Tecnológica de Colombia, Colombia \\ juandiegouptc@gmail.com \\ ROBERTO CREMADES ANDREU*** \\ Universidad Complutense de Madrid, España \\ rcremades@edu.ucm.es
}

Recepción: 24 de septiembre de 2016

Aprobación: 08 de noviembre de 2016

Forma de citar este artículo: Cárdenas Soler, R.N., Martínez Álvarez, J.D., \& Cremades Andreu, R. (2017). Competencias de lectura y escritura en música. Una propuesta para su asimilación en el currículo escolar. Cuadernos de Lingüística Hispánica, (29), 181-201. doi: http://dx.doi.org/10.19053/0121053X.n29.2017.5859

* Artículo de reflexión producto del proyecto de investigación «"Leo y escribo la música que toco". Análisis del proceso de apropiación de la competencia lecto-escritora musical, en estudiantes del taller de música, de Básica Secundaria, en la Institución Educativa Fundación Pedagógica Rayuela de Tunja».

** Doctora en Educación Musical, Universidad de Granada - España. Profesor Asociado, Universidad Pedagógica y Tecnológica de Colombia. Grupo de Investigación CACAENTA. Código ORCID: orcid.org/0000-0003-4997-4116

*** Licenciado en Música, Universidad Pedagógica y Tecnológica de Colombia. Grupo de Investigación CACAENTA.

***** Doctor por la Universidad de Granada con mención de Doctor Europeus. Profesor Contratado Doctor y Secretario Académico en la Universidad Complutense de Madrid - España. Grupo de Investigación HUM - 742 DEDiCA. Código ORCID: orcid.org/0000-00029930-1609 


\title{
Resumen
}

La música llega sin reservas a todos sus oyentes, partiendo del uso de los signos para la composición y pasando por la decodificación para llegar a la interpretación del mensaje musical. Por esta razón, se puede decir que la música es una lengua no materna, que sin conocer su código puede ser asimilada por cualquier persona. En este artículo se pretende analizar el concepto de competencias de lectura y escritura en música, situándolo específicamente en el campo de la lectura y la escritura de la lengua, entendiendo que la música se vale de signos y códigos aplicables a estas habilidades comunicativas (leer, escribir). Producto de dicho análisis se presenta, al finalizar el documento, una propuesta de estructuración de la competencia de lectura y escritura musical para un currículo escolar. Con este planteamiento se pretende aportar a la discusión sobre el deber ser de la educación musical en la escuela.

Palabras clave: lectura y escritura, música, competencias, educación musical.

\section{Reading and Writing Competences in Music. An Approach to their Incorporation into the School Curriculum}

\begin{abstract}
Music is a language that is able to reach all of its listeners. It emerges from the use of musical notation for its composition, and passes through a decoding process, to finally obtain an interpretation of the musical message. For this reason, it can be said that music is a non-native language, one that can be understood by anyone without needing to know its code. In this article an analysis of the concept of reading and writing competences in music is proposed, locating it specifically in the field of reading and writing in language, understanding that music uses a system of signs and codes which may be applied to the aforementioned communicative skills. As a result of this analysis, an approach to the incorporation of reading and writing competences in music is proposed for the school curriculum. This project aims at contributing to the discussion about the way musical education should be implemented in schools.
\end{abstract}

Key words: Reading and Writing, Music, Competences, Musical Education. 


\section{Compétences de lecture et d'écriture en musique. Une proposition pour leur assimilation dans le curriculum scolaire}

\section{Résumé}

La musique arrive sans réserves à tous ses auditeurs; en partant de l'utilisation des signes par la composition et en passant par la décodification pour arriver à l'interprétation du message musical. Pour cette raison, on peut dire que la musique est une langue nonmaternelle, que sans connaître son code, peut être assimilée par quiconque. Dans cet article, on prétend analyser le concept de compétences de lecture et d'écriture en musique, en le situant spécifiquement dans le domaine de la lecture et de l'écriture de la langue, en comprenant que la musique fait recours aux signes et codes applicables à ces habiletés communicatives (lire, écrire). A la fin du document, et en tant que produit de l'analyse mentionnée ci-dessus, on présente une proposition de la compétence de lecture et d'écriture musicale pour un curriculum scolaire. Avec cette approche, on prétend faire des apports à la discussion sur le devoir être de l'éducation musicale à l'école.

Mots clés: lecture et écriture, musique, compétences, éducation musicale.

\section{Competências de leitura e escritura na música. Uma proposta para sua assimilação no currículo escolar}

\section{Resumo}

A música chega sem reservas a todos seus ouvintes; partindo do uso dos sinais para a composição e passando pela decodificação para chegar à interpretação da mensagem musical. Por esta razão, pode-se dizer que a música é uma língua não materna, que sem conhecer seu código pode ser assimilada por qualquer pessoa. Neste artigo pretendese analisar 0 conceito de competências de leitura e escritura na música, situando-o especificamente no campo da leitura e da escritura da língua, entendendo que a música usa sinais e códigos aplicáveis a estas habilidades comunicativas (ler, escrever). Produto de tal análise apresenta-se, ao finalizar o documento, uma proposta de estruturação da competência de leitura e escritura musical para um currículo escolar. Com esta abordagem se pretende contribuir à discussão sobre o dever-ser da educação musical na escola.

Palavras chave: leitura e escritura, música, competências, educação musical. 


\section{Introducción}

En la comunicación humana existen signos y símbolos que representan situaciones sociales propicias para favorecer la interacción de los sujetos. Es así como dichos signos coadyuvan a la construcción significativa de identidades sociales y culturales (Hallyday, 1982). Lavignac, el ilustre maestro de armonía, a principios del siglo XX, manifestó que la música, al ser lengua, arte y ciencia, debería considerarse y estudiarse, según las circunstancias, bajo los parámetros de alguno de dichos aspectos (Lago, 2008). En el mismo sentido, Román (2008), quien considera investigaciones de teóricos musicales tales como la de Pierre Schaeffer (1996) dentro del soporte conceptual de su obra, declara que hay un consenso en que la música tiene significado y que existe un lenguaje de la música, el cual intrínsecamente comunica emociones.

Considerar la música como un lenguaje de comunicación, que se adapta parcialmente a los parámetros: finitud de signos, repertorio-léxico y sintaxis musical, posibilita su vinculación a un sistema semiótico (Cárdenas \& Martínez, 2015) que según Charles Pierce (1988), se estructura en tres partes: gramática (sintaxis), lógica (semántica) y retórica (pragmática) (Lada, 2001). Martínez (2007), hablando de la semiótica de la música, comenta que solo es hasta después de mediados del siglo XX que se conocen estudios relacionados con la significación de la música, realizados con fundamentos semióticos, como los de Jean Jacques Nattiez (1975) y Eero Tarasti (1994).

En todas las culturas y sociedades se presenta una situación similar, y es que sus individuos se unen en un ritmo o una melodía sencilla que evoluciona de un lenguaje único y universal de sonidos, y que permite y facilita la expresión y comunicación entre los sujetos, asimismo les identifica y les une, y en algunos casos, también les permite crear (Lago, 2008).

Toda idea musical trae consigo un mensaje, como cualquier otra forma de discurso. Un ejemplo claro es la música programática, en la que el autor representa o cuenta una historia y construye su música sobre ella, expresando así las emociones o significados que una producción literaria o pictórica tal vez no puede mostrar. En este sentido, Rojas (2003) expone tres formas de expresión musical: música absoluta, que es la que no hace mención a asuntos externos a ella, es decir, que solo expresa verdades musicales; música programática, que es la que se vale de formas externas a ella (literatura, pintura, 
etc.) para representar una idea musical; y música incidental, que es la que intenta de alguna forma entrelazar los otros dos tipos de obra creativa. No obstante, cada una de estas composiciones busca lo mismo, contar algo, exteriorizar una idea extra 0 intra musical, lo cual en este texto se quiere nombrar como mensaje, el cual llega al espectador sin reservas, como un lenguaje que no discrimina nacionalidad ni cultura, es decir, que permite ser asimilado sin ser la lengua materna de su oyente.

El Ministerio de Educación Nacional colombiano (MEN), desde comienzos del presente siglo XXI, ha venido planteando las directrices para el desarrollo de las diferentes áreas del conocimiento en las instituciones educativas de Básica (Primaria y Secundaria) y Media, enmarcando dichas directrices en el currículo por competencias. Es así como en el área de Artística, definida como obligatoria y fundamental por la Ley General de Educación, Ley 115 (Congreso de la República de Colombia, 1994), el último documento que se ha promulgado es el de "Orientaciones Pedagógicas para la Educación Artística en Básica y Media” (Cuéllar \& Effio, 2010), dentro del cual se contempla la educación musical, además de artes visuales, teatro y danza.

Sin embargo, pese a todos estos planteamientos, la educación musical, al igual que sucede con toda la educación artística, sigue siendo un privilegio, porque solo algunas instituciones educativas de carácter público cuentan con un profesor especialista en el área, que pueda desarrollar procesos pedagógicos musicales y, a su vez, competencias musicales en los estudiantes. Este escenario es un tanto diferente para las instituciones privadas, que pueden contratar docentes idóneos en cada una de estas áreas artísticas para que desarrollen lo propio (Lorenzo \& Cárdenas, 2010; Morales, 2006).

Es posible constatar, que en el sistema educativo formal los estudiantes no encuentran sentido en la apropiación de elementos inherentes a la notación musical, aplicados a la interpretación de la música que disfrutan, sino que utilizan otras grafías para señalar aquello que escuchan y que luego quieren reproducir (Carrasco, 2012; Peñalver, 2012; Porcel, 2010), queriendo hacer referencia aquí a las competencias de lectura y escritura en música. En este mismo sentido, el documento "Orientaciones Pedagógicas para el Área Artística" hace referencia al desarrollo de competencias específicas en las artes (sensibilidad, apreciación estética y comunicación) a partir de tres procesos: recepción, creación y socialización; todo ello contemplado dentro de las competencias básicas que deben desarrollar los estudiantes de los niveles educativos de Básica (Primaria y Secundaria) y Media. Es aquí donde cobra relevancia el planteamiento de la estructura de la competencia de lectura y escritura en música, que se encuentra vagamente descrita en las misivas del Ministerio de Educación Nacional de Colombia. 
En este documento, que es producto de la investigación intitulada «"Leo y escribo la música que toco", análisis del proceso de apropiación de la competencia lecto-escritora musical, en estudiantes del taller de música, de Básica Secundaria, en la Institución Educativa Fundación Pedagógica Rayuela de Tunja (Boyacá, Colombia)», se pretende plantear una posible estructuración de la competencia de lectura y escritura en música, para que sea tenida en cuenta en los procesos de educación musical en un currículo escolar.

\section{Lectura y audición en el lenguaje musical como forma de comunicación}

Etimológicamente, comunicar viene del latín cummunicare, que quiere decir compartir algo o hacerlo común, es decir, dar a conocer una idea a los semejantes (Frías, 2000); en este mismo sentido, los procesos de interpretación y audición musical se relacionan con el concepto referido al proceso de comunicación. Eco (1994) describe la comunicación como una característica humana que involucra cinco elementos: fuente, emisor, canal, mensaje y destinatario. Estos mismos elementos pueden asimilarse en el proceso de comunicación musical, por ejemplo: emisor es el intérprete o compositor; mensaje, la composición u obra musical; y destinatario, el oyente o público receptor. De esta forma, manifiesta Jorquera (2002):

[...] creo que es de sumo interés profundizar en cómo se desarrollan los procesos de aprendizaje de la lectoescritura del lenguaje verbal, para poder comprender adecuadamente los fenómenos propios del aprendizaje de la lectoescritura musical. (p. 1).

Para Gottfried Herder (1982), quien amplió su concepto más allá de la gramática, el lenguaje no es solo un instrumento de pensamiento sino que "es acopio y forma". Acopio porque los seres humanos se sirven de él para conservar su memoria (oral 0 escrita) y forma porque es un elemento para vehiculizar los pensamientos de los sujetos y sus representaciones del mundo (Tobón de Castro, 2007).

Según Stubley (1992), el conocimiento musical es un saber no proposicional que se evidencia a través de la audición, la ejecución instrumental y la creación musical, no necesariamente a partir del lenguaje, tesis que puede justificar el hecho de que en el documento "Orientaciones Pedagógicas para el Área Artística", en relación con la formación musical, no se incluyera la competencia de lectura y escritura musical, de manera específica. De igual manera, Rusinek (2006) manifiesta: 
Saber música procedimentalmente implica, entonces, ser capaces de lograr representaciones mentales de la música que escuchamos - la cognición auditiva-, ser capaces de ejecutar música -cantando o tocando- y ser capaces de crear música -improvisando o componiendo-. (p. 16).

Aquello que una persona escribe usando el código musical será interpretado por ella o por otra en cualquier lugar del mundo, sin considerar la situación de su lengua nativa, porque el lenguaje musical maneja códigos y signos comprendidos universalmente. Esto es posible porque el lenguaje musical cuenta con su propio sistema lingüístico, con el cual puede comunicar experiencias, emociones y sentimientos (Porcel, 2010).

En Colombia existe el Plan Nacional de Lectura y Escritura, de Educación Inicial, Preescolar, Básica y Media, el cual surge a partir del interés por formar ciudadanos que puedan afrontar adecuadamente las exigencias que les propone la sociedad actual (Ministerio de Educación Nacional de Colombia, 2011). Dicho Plan concibe la lectura, más allá de la decodificación, como un proceso de construcción de significados por parte del lector, basado en el texto y el contexto. Si se aplica este concepto de lectura al lenguaje musical, se podría notar que hay un estadio necesario de decodificación de signos, para pasar a entender que dentro de una composición musical el autor espera que haya una comprensión y significación del mensaje plasmado en su obra, más allá del código, en el mismo sentido que Fons (2004) le confiere al proceso de lectura prosódica: "Leer es un proceso activo, porque quien lee debe construir el significado del texto interactuando con él” (p. 21).

A su vez, Fons, referenciando a Isabel Solé (1987) plantea cuatro acepciones de lo que se entiende por leer, las cuales también tienen aplicación en el lenguaje musical: leer es un proceso activo, leer es conseguir un objetivo, leer es un proceso de interacción entre quien lee y el texto, y leer es implicarse dentro de un proceso de predicción e inferencia continua. En cuanto "proceso activo y proceso de interacción entre quien lee y el texto", no necesariamente quien lee replica el significado que el autor quiso darle a su obra, situación que también sucede en una representación musical, donde la sensación que el autor quiere dar dentro de su composición no siempre corresponde a la que el intérprete dinamiza 0 a la que los oyentes reciben, pero no niega la existencia del mensaje, tal y como lo expone Orlandini (2012), refiriéndose al hecho interpretativo musical.

Schultz (1996) se refiere a diversos niveles de lectura musical y plantea que además de que el lector musical debe realizar una decodificación compleja (íconos reguladores de intensidad, mordentes, apoyaturas, etc.-, índices -da capo, al signo, ritardando, etc.-, símbolos -figuras musicales, alturas, divisiones de compás, etc.-), 
cuando la lectura es performática implica una realización simultánea de lo que lee, desde la ejecución técnica - motora, es decir que intervienen en el ejercicio lector tres funciones: lógica (decodificación), kinético-energética (motora) y emocional (expresiva). Para el planteamiento de la competencia de lectura y escritura en música, que se propone en este artículo, se consideran estos diversos niveles de apropiación de dicha habilidad, porque no es lo mismo leer una partitura, a manera de estudio, que leerla en un acto público 0 presentación musical, a través de la interpretación con un instrumento.

La anterior explicación pone en evidencia cómo dentro de la pieza musical están los tres actores del proceso comunicativo, emisor, mensaje y receptor; además, que hay diferentes niveles de lectura musical, atendiendo a las consideraciones de la obra 0 composición, hecho que exige del lector determinadas habilidades y un conocimiento suficiente del lenguaje musical, además de otros elementos contextuales que le permitan apropiación para la adecuada interpretación.

\section{Escritura y lenguaje musical}

Como lo plantearan Olson (1977) y Defior (2000), la escritura permitió la civilización de los seres humanos, siendo uno de sus más grandes logros, ya que el lenguaje escrito separa al hombre de la prehistoria y lo incluye en la historia, dejando entrever que la escritura es un elemento de dominación y poder. En el campo de la música esta apreciación también es posible, ya que es comúnmente aceptado que cuando se dice que un individuo sabe música se hace referencia al dominio del lenguaje musical y a la posibilidad técnica para interpretar un instrumento musical (Rusinek, 2006). Asimismo, gracias a la codificación musical, tal y como lo exponen Buj (2014) y Carrasco (2012), se puede establecer la historia de la música en sus diferentes épocas, a partir de la evolución en el uso de un sistema de signos que cada vez es más complejo.

Para establecer un significado de escritura y lenguaje en música, es preciso atender a los conceptos trazados en el campo del lenguaje articulado. "Escribir es el proceso mediante el cual se produce un texto escrito" (Fons, 2004, p. 22). La "escritura se define como la representación de las palabras o del pensamiento con letras o con símbolos trazados [...] Es a la vez la escritura práctica y lenguaje" (Ferrández \& Gairín, 1985, p. 11). "A diferencia de la lectura $[\ldots]$ la escritura mantiene su carácter elitista. Solo una minoría escribe $[\ldots]$ manejando diversos tipos de textos [...] la escritura sigue asociada al poder [...] aun cuando este sea simbólico (Ministerio de Educación Nacional de Colombia, 2011, p. 15). 
Mientras que en la lectura se distinguen los procesos de decodificación y comprensión, en la escritura están los de codificación, mediante signos escritos, y los de composición (Defior, 2000). Así, puede entenderse el signo como un elemento portador de un discurso. Para Foucault, los signos son símbolos que responden a una función ordenadora, inconsciente y generalizada para la raza humana, sin embargo, son dependientes del espacio, tiempo, otros signos y la propia cultura (García del Pozo, 1987). Retomando a Eco (1994), el signo es:

Línea, figura 0 algo parecido que se traza para señalar el punto al que se ha llegado. Todos los signos de esta categoría pueden indicarse con un sinónimo aparente de signo, que es señal [...] Cualquier expresión gráfica, punto, línea, recta, curva y otras similares adoptadas convencionalmente para representar un objeto abstracto [...] En determinados contextos se llama también símbolo. (p. 13).

Mientras que en cualquier lengua es justificada la obligatoriedad del aprendizaje de su forma escritural (un ejemplo de ello es el establecimiento del Plan Nacional de Lectura y Escritura de educación Inicial, Preescolar, Básica y Media, en Colombia), en la educación musical no existe una exigencia similar, porque la notación musical no es una característica propia de todas las prácticas musicales (Jorquera, 2002), que en muchas culturas solo son de tradición oral, como lo expone Martínez (2014), en relación con la investigación realizada a un grupo musical de la zona pacífica colombiana, quienes, entre otras actividades tradicionales, elaboran sus propios instrumentos (de manera artesanal) e interpretan músicas autóctonas para fortalecer vínculos de identidad.

Refiriéndose al signo en música, Schultz (1996) hablaba de íconos, índices y símbolos, mientras que Porcel (2010) hacía la siguiente clasificación: signos de entonación (pentagrama, líneas adicionales, claves, alteraciones), signos de duración (figuras y silencios, prolongaciones -ligaruda, puntillo, calderón-, compás -binario, ternario, cuaternario-, agógica -lento, largo, allegro, etc.-), y signos de expresión (matices o dinámica, fraseo, acentuaciones, carácter, articulaciones).

En conclusión, el lenguaje musical se ha apropiado de una serie de signos, considerando los primeros neumas introducidos, posiblemente, por el papa Gregorio I (540-604), y posteriormente una notación alfabética (Balbulus Notker, 830-912 y Hucbaid de Saint Amand, 840-931). Sin embargo, es Guido d'Arezzo (995-1050) quien introduce la disposición de signos que se conoce y maneja hoy día como herramientas para la comunicación escrita del discurso musical (Cox, 2004). Algunos de estos signos se muestran en la tabla 1, la cual no incluye el nombre de las notas (DO, RE, MI, FA, SOL, LA, SI). 
Tabla 1. Algunos signos usados en el lenguaje musical

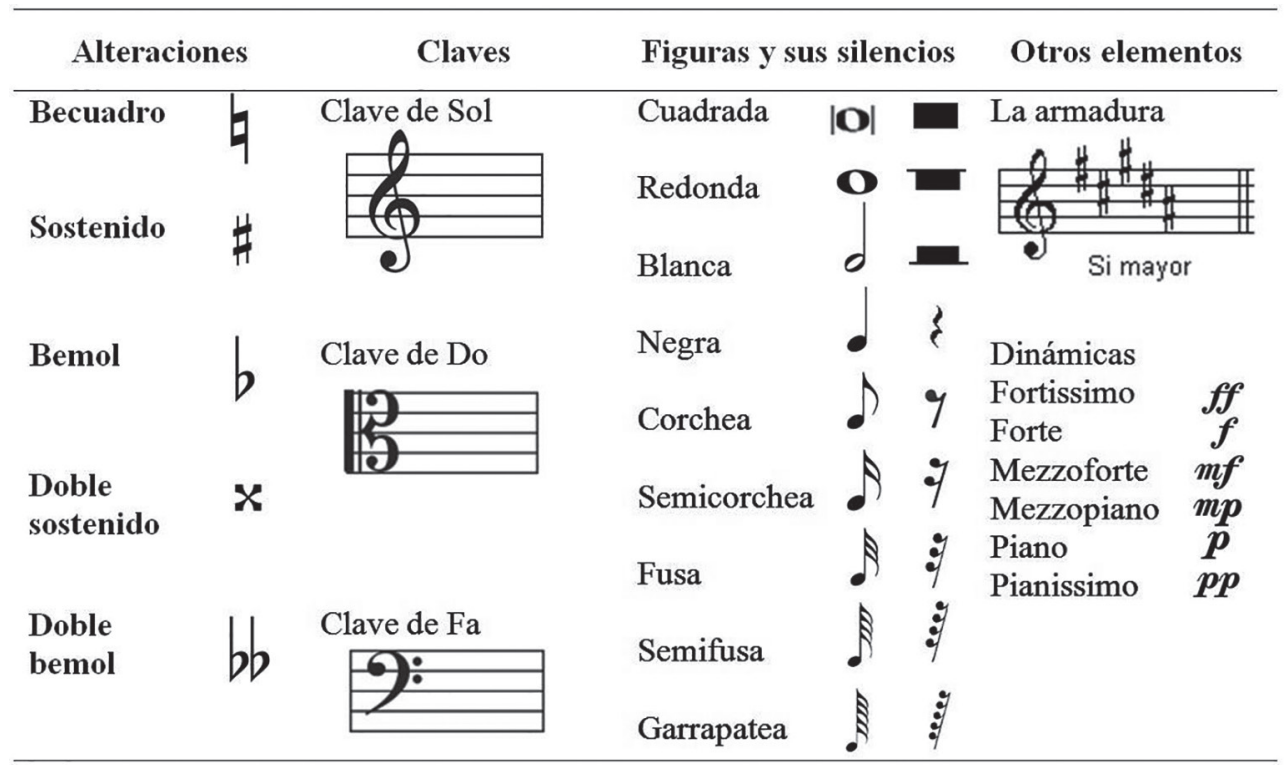

El contenido de la tabla 1 muestra el signo tanto como semainon (entendido como el estímulo visual) como semainomenon (aspecto representacional o la significación del mismo), que en su unión dan lugar al mensaje, en términos de Gamkrelidze (2007).

Estos signos establecen principios de coherencia en un motivo musical. Con su desarrollo estructuran la representación escrita del discurso musical, visto como una idea plasmada en la partitura, donde se puede observar cómo cada frase revela una cantidad de signos que buscan comunicar un pensamiento musical. Aunque cada uno de ellos tenga un significado diferente, en su conjunto organizan una idea coherente. Según lo plantean López, Shifres y Vargas (2005) "Ver la música como texto implica que el objeto de conocimiento es lo que queda escrito" (p. 242), pensamiento que está arraigado en la educación musical o enseñanza tradicional de la música que se focaliza en la lectura y la escritura, en el aprendizaje del código musical.

Borregales (2005) plantea un ejemplo de lo que sería comparar el análisis gramatical de una frase simple con el de una idea musical. Es así como establece una similitud entre: enunciado, cláusula, sintagma, palabra y morfema, para el caso del análisis lingüístico de la frase "Carlos rompió la ventana" y, en relación con la sintaxis-musical: idea musical, frase, semifrase, motivo y célula. 
[...] con la música al igual que con el lenguaje se crea discurso [...] portador de un mensaje que se ve afectado y de alguna manera revela el entorno de quien lo crea [...] Se trata de dos tipos de comunicación que [...] comparten muchas características. (Borregales, 2005, p. 71).

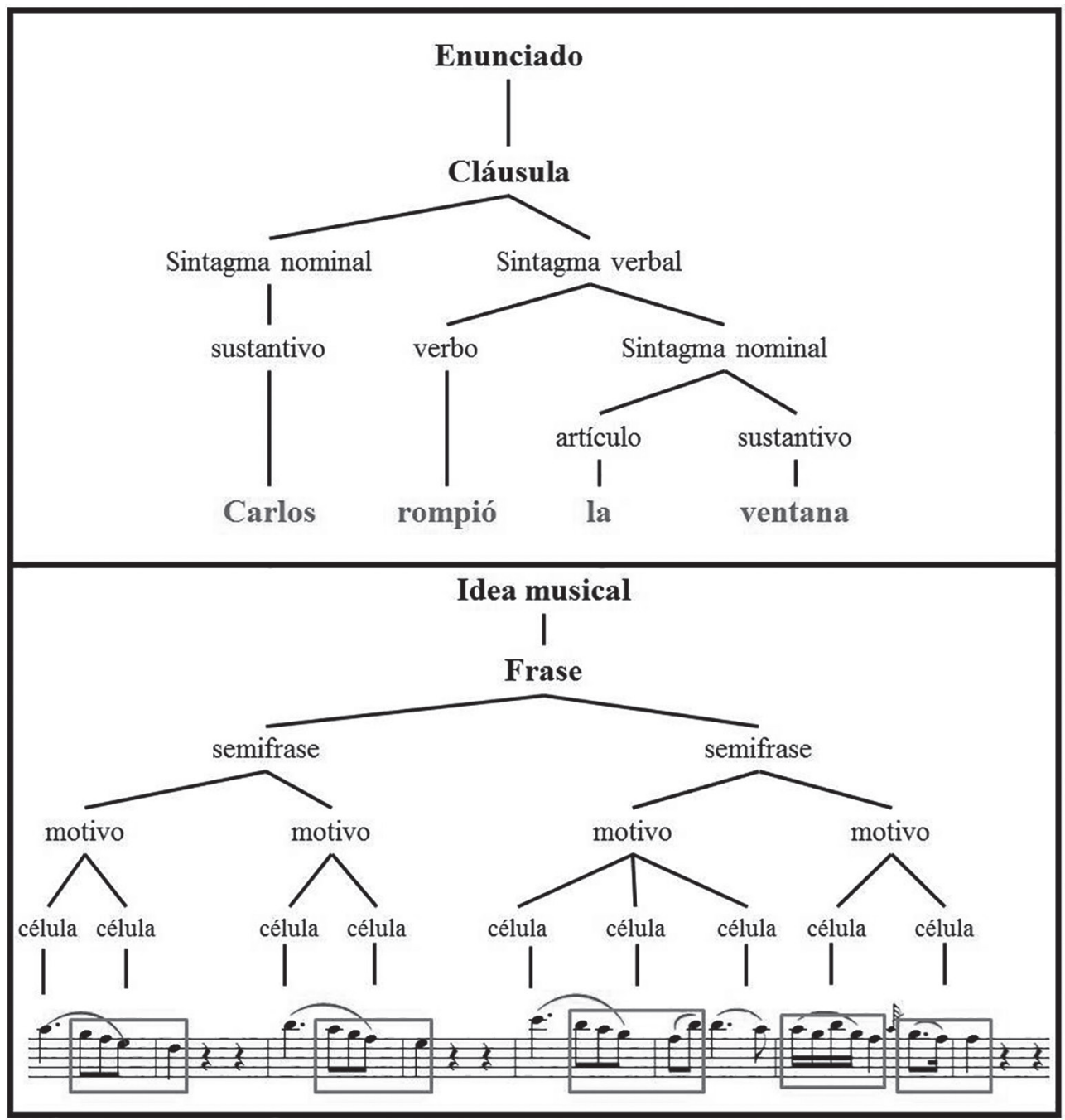

Figura 1. Comparación entre el análisis de una oración y el de una frase musical (Fuente Borregales, 2005, pp. 12, 30)

Esta misma idea es utilizada por Pérez (2000), para señalar la similitud existente entre la estructura musical y el lenguaje gramatical en relación con la estructura y el fraseo, 
de manera que: (a) la letra equivaldría a la nota musical, (b) la silaba-palabra al motivo o inciso, (c) la frase gramatical a la frase musical, (d) la oración al período, (e) el parágrafo a la sección, (f) el capítulo al movimiento, (g) la obra a la obra musical y por último, (h) las puntuaciones serían los puntos cadenciales con los que en música distinguimos las frases musicales.

De la misma forma, se puede analizar la similitud en la estructura de ambos lenguajes, donde resalta la forma en que se agrupan los signos, permitiendo generar una idea gramatical. Así, "El mensaje equivale al signo. En realidad, un mensaje puede ser la organización compleja de muchos signos" (Eco, 1994, p. 29). Tanto los signos musicales (redondas, blancas, negras, etc.) como los gramaticales (vocales, consonante, puntos, etc.) comienzan y estructuran un mensaje escrito. De esta forma, la composición musical se puede entender como sinónima del texto escrito, ya que la codificación de la idea musical se hace efectiva en el trazo de signo, convirtiéndose este ejercicio en una práctica propia del lenguaje.

En la escritura musical se podrían aplicar y explicar los tres procesos mencionados por Fons (2004), como propios de la creación de un discurso musical, es decir la planificación, como el proceso mediante el cual el compositor se apropia de una idea musical (ya sea durante el proceso de escritura o previo al mismo), podría simplemente imaginarse un motivo musical; posteriormente, durante la textualización se realizaría la transcripción, en físico, de esa idea musical o motivo, procurando la respectiva conducción armónica y melódica, definición del tempo, de los matices, de los instrumentos musicales que interpretarán la obra, etc.; y por último, en la etapa de revisión se plantearían aspectos de edición del discurso musical.

\section{Las competencias en educación}

Ser competente para la Organización para la Cooperación y el Desarrollo Económico - OCDE, proyecto DeSeCo Definición y selección de competencias - teoría y fundamentos conceptuales, significa la combinación de habilidades, conocimientos, motivaciones y valores dirigidos a desarrollar una actividad adecuada y pertinentemente (2005); mientras que en la Oficina Internacional de la UNESCO, Aguerrondo (2009) manifiesta que al haber nacido este concepto en la reflexión sobre la formación profesional y su efectividad en el desempeño laboral, se han generado bastantes controversias durante su aplicación en el campo educativo, enumerando múltiples acepciones "la capacidad, expresada mediante los conocimientos, las habilidades y las actitudes que se requieren para ejecutar una tarea de manera inteligente, en un entorno real o en otro contexto" (p. 7). 
Los currículos por competencias no solo buscan dar herramientas específicas a las personas, también buscan modificar la forma de actuar de las mismas, ya que llevan los estándares 0 ideales de conocimientos adecuados hacia la formación de una persona ideal. En términos de Tadeu da Silva (1999), el concepto de competencia surge de las respuestas a las preguntas " ¿Cuál es el tipo de ser humano deseable para un determinado tipo de sociedad? ¿Será la persona racional e ilustrada del sistema humanista? ¿Será la persona competitiva de los actuales modelos educativos neoliberales?" (p. 12).

Las reformas educativas llevadas a cabo en los países latinoamericanos, en la década de los años 90s, se centraron en el debate del mejoramiento de la calidad de los aprendizajes desarrollados por niños y jóvenes (Braslavsky, 1995). Particularmente en Colombia, durante el gobierno de César Gaviria se asume la reestructuración del sistema educativo con la promulgación de la Ley General de Educación y se toma la decisión de evaluar la educación para generar apertura educativa. En consecuencia, se constituyen las políticas que dieron lugar a la formación por competencias en toda la extensión del país, con la Resolución 2343 de 1996, que instaura la evaluación de las competencias a través de los y el planteamiento de los lineamientos generales para los procesos curriculares (Ministerio de Educación Nacional de Colombia, 1996). Se habla de competencia como un desempeño observable, verificable o efectivo, a partir de los niveles de desempeño: superior, alto, básico y bajo, porque el término competencia está asociado con evaluación.

La educación por competencias viene específicamente de las propuestas de investigadores del siglo XX, tales como Noam Chomsky, Jean Piaget, Lev Vygotski, David Ausubel y Howard Gardner (Organista, 2007). Tobón (2006) propone el siguiente concepto: competencias son procesos - con inicio y final-complejos -multidimensionales- de desempeño-actuación real-con idoneidad-criterios de eficacia, eficiencia, efectividad, pertinencia y apropiación - en un determinado contexto -campo disciplinar, social o cultura-, con responsabilidad -analizar antes de actuar-. Dell Hymes complementa este concepto planteando la competencia comunicativa que, incluyendo aspectos cognoscitivos, otorga mayor relevancia a los motivantes que propician el habla, especialmente ubicados en los espacios socioculturales, es decir que la competencia adquiere un valor profundo en el momento de ser usada, antes de dicha actuación y de la demostración de una habilidad neurofisiológica no tiene sentido (Bernal \& Giraldo, 2004).

Según Fernández-Salinero (2006), existen tres tipos de competencia: básicas, genéricas y específicas. Básicas son: comunicativa (interpretar y producir textos con sentido, coherencia y cohesión); matemática (resolver problemas matemáticos sencillos e interpretar la información que contenga lenguaje matemático); autogestión del proyecto ético de vida; manejo de nuevas tecnologías de la información y la comunicación; 
liderazgo y asunción; y adaptación al cambio. Las competencias genéricas facilitan el intercambio entre varias ocupaciones, laborales o profesiones, y las específicas, que son las habilidades directas de una ocupación o profesión determinada.

A la anterior clasificación, el Ministerio de Educación Nacional de Colombia, agrega una serie de competencias propias de cada una de las áreas de formación, a partir del establecimiento de los Lineamientos Curriculares, con posterioridad a 1998. El área de educación artística también es integrada a este planteamiento de orientaciones gubernamentales, ya que el gobierno nacional concibe las artes como un coadyuvante a la formación humanística, no pensada específicamente para el ejercicio laboral, sino para la construcción del sujeto como un ser humano íntegro y reflexivo para desenvolverse en las diferentes condiciones de la sociedad (Ministerio de Educación Nacional de Colombia, 2000).

El documento Lineamientos Curriculares para el Área Artística se refiere al desarrollo de ocho competencias: percepción de relaciones; atención al detalle; multiplicidad de respuestas ante un problema; habilidad para cambiar la direccionalidad cuando aún se está en proceso; habilidad para tomar decisiones en ausencia de reglas; habilidad de predicción; habilidad de creatividad frente a la limitación del contexto; y habilidad para observar desde un punto de vista ético y estético (Ministerio de Educación Nacional de Colombia, 2000). Posteriormente, Cuéllar y Effio (2010) identifican tres competencias: sensibilidad, apreciación estética y comunicación; a través de los procesos de: recepción, creación y socialización.

\section{Construcción del concepto de competencias de lectura y escritura en música}

Para la incorporación de la música dentro de los currículos escolares, es importante considerar la necesidad de encontrar formas de estructuración que estén en concordancia con las políticas educativas actuales. Dicha consideración parte del anterior análisis del sistema educativo por competencias y su asociación con las prácticas musicales, tal y como lo refleja la normativa:

La formulación de las competencias genéricas para la educación superior constituye una tarea que el Ministerio de Educación Nacional de Colombia ha emprendido como parte de sus estrategias para establecer referentes comunes que garanticen la calidad de la formación en nuestro país, así como la articulación de los distintos niveles de la educación: inicial, básica, media y superior. (Ministerio de Educación Nacional de Colombia, 2009, p. 1). 
De esta forma, para estructurar las competencias de lectura y escritura en música que se propone en la tabla 2 se ha tomado como referente, además de los planteamientos de Tobón (2006), los conceptos establecidos por el Ministerio de Educación Nacional de Colombia, para el caso de la lectura y la escritura, en las competencias en Lengua Castellana, con la definición que se advierte a continuación:

[...] el acto de leer se entenderá como un proceso significativo y semiótico cultural e históricamente situado, complejo, que va más allá de la búsqueda del significado y que en última instancia configura al sujeto lector. [Escribir no es solo] [...] una codificación de significados a través de reglas lingüísticas. Se trata de un proceso que a la vez es social e individual en el que se configura un mundo y se ponen en juego saberes, competencias, intereses, y que a la vez está determinado por un contexto socio-cultural y pragmático que determina el acto de escribir: escribir es producir el mundo. (Ministerio de Educación Nacional de Colombia, 1998, p. 27).

También se consideran los Lineamientos Curriculares para la Educación Artística, que se supone están siendo implementados en las instituciones educativas, pero que son demasiado ambiciosos en contenido y propósitos, razón por la cual no encuentran una total aceptación dentro de los Proyectos Educativos Institucionales, situación que se convierte en una debilidad para el cumplimiento de los fines formativos de la Educación Artística (Ministerio de Educación Nacional de Colombia, 2000).

Por último, se parte del análisis de que ni estos Lineamientos Curriculares ni las Orientaciones Pedagógicas abordan con suficiente propiedad las competencias de lectura y escritura en música, es así como la siguiente propuesta pretende constituirse en un referente para involucrar dicha competencia en el currículo escolar.

Las competencias de lectura y escritura en música pueden ubicarse tanto en las competencias específicas, como en las básicas y las genéricas. En las específicas atendiendo a las características propias del sistema de signos que estructuran la teoría musical; como competencia básica se entendería su función dentro de una forma eficiente de comunicación que facilitara la relación con otros sujetos; y como competencia genérica propendería hacia el trabajo en equipo, el uso de recursos, la capacidad de emprendimiento, etc. 


\section{Tabla 2. Competencias de lectura y escritura musical}

\begin{tabular}{|c|c|}
\hline $\begin{array}{l}\text { 1. Identificación de } \\
\text { la competencia }\end{array}$ & $\begin{array}{l}\text { Saber reconocer e interpretar el código musical (grafía musical convencional) } \\
\text { teniendo en cuenta los diferentes aspectos teóricos y musicales del mismo. }\end{array}$ \\
\hline \multirow{4}{*}{$\begin{array}{l}\text { 1.1. Elementos de } \\
\text { competencia }\end{array}$} & $\begin{array}{l}\text { Leer el código musical (grafía musical convencional), comprendiendo de forma } \\
\text { básica y eficiente su significado. }\end{array}$ \\
\hline & $\begin{array}{l}\text { Escribir el código musical (grafía musical convencional), comprendiendo de forma } \\
\text { básica y eficiente su significado. }\end{array}$ \\
\hline & $\begin{array}{l}\text { La capacidad básica de representar ideas o discursos musicales por medio del uso } \\
\text { del código musical. }\end{array}$ \\
\hline & $\begin{array}{l}\text { La capacidad básica de reconocer y representar la grafía musical convenciona } \\
\text { escrita respetando su representación teórica. }\end{array}$ \\
\hline \multirow{6}{*}{$\begin{array}{l}\text { 1.2. Criterios de } \\
\text { desempeño }\end{array}$} & $\begin{array}{l}\text { La capacidad básica de identificar auditivamente esquemas musicales sencillos } \\
\text { trasladarlos a un texto escrito respetando su representación teórica. }\end{array}$ \\
\hline & $\begin{array}{l}\text { La capacidad básica de interpretar fragmentos musicales, en espacios prácticos } \\
\text { musicales, ya sea en el ámbito instrumental o vocal. }\end{array}$ \\
\hline & $\begin{array}{l}\text { La capacidad básica de interpretar obras sencillas, asumiendo la diferencia de } \\
\text { contextos y pensamientos en el momento de entender la idea musical del autor c } \\
\text { la representación subjetiva del discurso musical. }\end{array}$ \\
\hline & Saber conocer y saber hacer \\
\hline & $\begin{array}{l}\text { Conocimiento de símbolos musicales básicos, como redonda, blanca, negra } \\
\text { corchea, semicorchea, con sus respectivos silencios, representación de matices } \\
\text { como: piano }(p) \text { mezzopiano }(m p) \text {, mezzoforte }(m f) \text {, forte }(f) \text {, y fortissimo (ff) } \\
\text { además de símbolos como crescendo o decrescendo, entre otros. }\end{array}$ \\
\hline & $\begin{array}{l}\text { Representación de símbolos musicales básicos, como redonda, blanca, negra } \\
\text { corchea, semicorchea, con sus respectivos silencios, y representación de matices } \\
\text { como: piano }(p) \text { mezzopiano }(m p) \text {, mezzoforte }(m f) \text {, forte }(f) \text {, y fortissimo (ff) } \\
\text { además de símbolos como crescendo o decrescendo, entre otros. }\end{array}$ \\
\hline \multirow{7}{*}{$\begin{array}{l}\text { 1.3. Conocimientos } \\
\text { y comprensiones } \\
\text { esenciales }\end{array}$} & $\begin{array}{l}\text { La utilización de los símbolos anteriores de manera coherente dentro de un } \\
\text { discurso musical. }\end{array}$ \\
\hline & $\begin{array}{l}\text { El reconocimiento de los códigos anteriores para la interpretación de una obra } \\
\text { musical sencilla. }\end{array}$ \\
\hline & Reconocimiento auditivo de los símbolos dentro de una idea musical. \\
\hline & $\begin{array}{l}\text { Discriminación de los símbolos logrando la comprensión de una idea musica } \\
\text { como discurso coherente. }\end{array}$ \\
\hline & Saber ser \\
\hline & Es crítico respecto a la interpretación personal de un discurso musical. \\
\hline & Es capaz de reconocer y valorar las obras creativas de sus compañeros. \\
\hline
\end{tabular}




\subsection{Rango de aplicación}

\subsection{Evidencias requeridas}

El campo de aplicación estará compuesto por espacios y prácticas tales como: escenarios, diversos contextos sociales, el quehacer musical como práctica solista o de conjunto, reconocimiento de ideas musicales asociadas con otras áreas artísticas, e interdisciplinariedad con diferentes áreas del conocimiento.

Evidencia de desempeño

Muestra capacidad para escribir al menos tres composiciones sencillas utilizando la grafía convencional de lectura y escritura musical.

Muestra capacidad de leer composiciones musicales sencillas, que utilizan grafía convencional de lectura y escritura musical.

Evidencia de conocimiento

Interpreta el significado de los signos musicales, desde su aspecto básico (signos específicos) hasta el más complejo (motivo y frases musicales).

Interpreta el significado del discurso musical.

Reconoce el significado de la idea que el autor le quiere asignar a un discurso musical en particular.

La importancia de la música radica en los diferentes beneficios que provee para los procesos particulares y pedagógicos de las personas, por ejemplo, en el desarrollo de las dimensiones social, cognitiva y emocional. Sin embargo, no solo estos beneficios justifican la práctica y educación musical en el contexto escolar, sino también el hecho de que la música ha estado presente en todos los contextos de desarrollo del ser humano, razón por la cual hace parte de sus tradiciones culturales, acervo histórico y desarrollo social; es decir que es tal vez la práctica artística que más se acerca y está presente en su diario vivir. Es así como, a partir de las actividades de audición musical, donde pueden mediar los procesos de lectura y escritura, los sujetos tienen la posibilidad de ampliar su espectro sonoro, además de reconocer sus propias expresiones artístico-musicales, tan cercanas a su cotidianidad.

\section{A manera de conclusión}

Después del análisis de las políticas educativas, las diferentes características del lenguaje musical, en conjunción con las bondades del estudio de las artes y el considerar la necesidad de incluir criterios claros y adecuados para la educación musical en Colombia, se concluyó que es necesario diseñar las competencias específicas para lectura y escritura en música, para los niveles de la educación Básica y Media. Este planteamiento permitirá estructurar un proceso educativo en la música, con contenidos que posibiliten un conocimiento real, desde las prácticas instrumentales, vocales y teóricas, atendiendo a la comprensión del arte musical como un lenguaje que permite, al igual que la lengua materna, la asimilación de un mensaje que es universalmente entendido. 
Nuestra pretensión es consolidar un currículo escolar que incluya procesos musicales más completos y coherentes en su estructuración teórica y práctica, y que se valgan del entendimiento de las características gramaticales correspondientes a cualquier lengua, de manera que estas les permitan a los estudiantes una fácil y efectiva aprehensión de los constructos musicales.

\section{Referencias bibliográficas}

Aguerrondo, I. (2009). Conocimiento complejo y competencias educativas. IBE Working Papers on Curriculum, 8, 1-13. Recuperado de http://www.ibe.unes co.org/fileadmin/user_upload/ Publications/Working_Papers/knowledge_compet_ibewpci_8.pdf

Bernal, J., \& Giraldo, G. (2004). Concepto de competencias en maestros del área de lengua castellana en Bogotá. Revista Enunciación, 1(9), 79-89.

Borregales, C. (2005). La música y el lenguaje como sistemas de comunicación comparables bajo la óptica del análisis del discurso. (Tesis de grado). Universidad Metropolitana, Caracas: Facultad de Ciencias y Artes, Escuela de Idiomas Modernos.

Braslavsky, C. (1995). La educación secundaria en el contexto de los cambios en los sistemas educativos lationamericanos. Revista Iberoamericana de Educación, 9(1), 91-123. Recuperado de http://www.rieoei.org/oeivirt/rie09a03.PDF

Buj, M. (2014). Partituras gráficas circulares. BRAC Barcelona Research Art Creation, 3(2), $277-$ 300.

Cárdenas, R., \& Martínez, D. (2015). El paisaje sonoro, una aproximación teórica desde la semiótica. Revista de Investigación, Desarrollo e Innovación, 5(2), 129-140.

Carrasco, I. (2012). Les grafies no convencionals: una eina d'estructuració del pensament musical i de composició a l'aula d'Educació Musical. Revista Electrònica d'Investigació $i$ Innovació Educativa $i$ Socioeducativa, 2(2), 128-150. Recuperado de https://dialnet.unirioja.es/ servlet/articulo? codigo $=4313314$

Congreso de la República de Colombia. Ley General de Educación, No 115. Bogotá, 1994. Diario oficial No 41214.

Cox, D. (2004). Music in the Time of Saint Anselm. The Saint Anselm Journal, 2(1), 90-98. Recuperado de http:www.anselm.edu/Documents/Institute\%20for\%2 0Saint\%20Anselm\%20 Studies/Abstracts/4.5.3.2i_21Cox.pdf 
Cuellar, A., \& Effio, M. (2010). Orientaciones pedagógicas para la educación artística. Ministerio de Educación Nacional. Recuperado de http://www.mine ducacion.gov.co/1759/articles-40033_ archivo_pdf_Orientaciones_Edu_Artis tica_Basica_Media.pdf

Defior, S. (2000). Las Dificultades de Aprendizaje: Un Enfoque Cognitivo: Lectura, Escritura, Matemáticas. Madrid: Ediciones Aljibe.

Eco, H. (1994). El signo. Bogotá: Letra E.

Fernández-Salinero, C. (2006). Las competencias en el marco de la convergencia europea: Un nuevo concepto para el diseño de programas educativos. Encounters in Theory and History of Education, 7(1), 131-153.

Ferrández, A. \& Gairín, J. (1985). Didáctica de la escritura. Barcelona: Editorial Humanitas.

Fons, M. (2004). Leer y escribir para vivir. Barcelona: Editorial Graó.

Frías, X. (2000). Introducción a la lingüística. Ianua. Revista Philologica Romanica, 1, 1-16. Recuperado de http://www.romaniaminor.net/ianua/sup/sup01.pdf

Gamkrelidze, T. (2007). The "Principle of Complementarity and the Nature of the Linguistic Sign. Bulletin of de Georgian National Academy of Sciences, 175(1), 168-174. Recuperado de http://www.science.org.ge/moambe/2007-vol3/gamkrelidze.pdf

García del Pozo, R. (1987). El signo y el pensamiento del exterior en una arqueología del conocimiento. Thémata Revista de Filosofía, 4(1), 39-48.

Hallyday, M. (1982). Lenguaje como semiótica social. México: Fondo de Cultura Económica.

Herder, J. H. (1982). Obra Selecta. Madrid: Alfaguara.

Jorquera, M. (2002). Lectoescritura musical: fundamentos para una didáctica. LEEME: Revista de la Lista Europea de Música en la Educacion, 10, 1-18. Recuperado de http://musica. rediris.es/leeme/revista/jorquera02b.pdf

Lada, U. (2001). La dimensión pragmática del signo literario. Revista Estudios Filológicos, 36(1), 61-70.

Lago, P. (2008). La música como ciencia, arte y cultura que aglutina, y como lenguaje que nos universaliza. Revista Prodiemus, 1(1), 1-13. Recuperado de http://www.prodiemus.com/ parlem/articles/0000106.pdf

López, I., Shifres, F., \& Vargas, G. (2005). La enseñanza del lenguaje musical y las concepciones acerca de la música. Actas de las Primeras Jornadas de Educación Auditiva. Provincia de Buenos Aires, Argentina, 1, 239-248. Recuperado de http:/www.aacademica.com/favio. shifres/142.pdf 
Lorenzo, 0., \& Cárdenas, R. N. (2010). Antecedentes y actualidad de la Música y la Educación Musical en Colombia. Arte y Ciencia, Creación y Responsabilidad, 1, 291-312.

Martínez, J. L. (2007). Semiótica de la música: una teoría basada en Peirce. Revista de la Asociación Española de Semiótica, 10(1), 177-192.

Martínez, O. G. (2014). África, memoria musical del río San Juan. Cuadernos de Música, Artes Visuales y Artes Escénicas, 1(9), 139-168.

Ministerio de Educación Nacional de Colombia. (1996). Resolución 2343. Por la cual se adopta un diseño de lineamientos generales de los procesos curriculares del servicio público educativo y se establecen los indicadores de logros curriculares para la educación formal. Bogotá: MEN.

Ministerio de Educación Nacional de Colombia. (1998). Lengua Castellana: Lineamientos Curriculares. Bogotá, D.C.: Cooperativa Editorial Magisterio.

Ministerio de Educación Nacional (2000). Lineamientos Curriculares para el Área Artística. Recuperado de http://www.mineducacion.gov.co/1621/articles-339975_recurso_4.pdf

Ministerio de Educación Nacional de Colombia. (2009). Educación Superior Boletín Informativo. Bogotá, D.C.

Ministerio de Educación Nacional de Colombia. (2011). Plan Nacional de Lectura y Escritura de educación Inicial, Preescolar, Básica y Media. Bogotá: Dirección de Calidad de Educación Preescolar, Básica y Media, Subdirección de Fomento y Competencias.

Morales, B. L. (2006). Música y currículo: análisis comparativo de los lineamientos curriculares de la Educación Básica en España y Colombia. Revista el Artista, 3(1), 142-160.

Nattiez, J. J. (1975). Fondements d'une sémiologie de la musique. París: Union Généale d'Éditions.

Olson, R. (1977). Hacia una valorización de lenguas minoritarias nacionales. La Paz: Instituto Boliviano de Cultura.

Organista, P. (2007). El concepto de competencias: una mirada histórica desde la psicología de la cognición. Cuadernos Hispanoamericanos de Psicología, 1(7), 69-76.

Organización para la Cooperación y el Desarrollo Económico - OCDE. (2005). The definition and selection of key competencies. Recuperado de http://www.oecd.org/pisa/35070367.pdf

Orlandini, R. (2012). La interpretación musical. Revista Musical Chilena, 66(218), 77-81.

Peñalver, J. M. (2012). Sistemas de notación musical alternativos (II). Una aproximación a la grafía del ritmo duracional. ArtsEduca, 3(1), 48-57. 
Pierce, Ch. (1988). El hombre, un signo (El pragmatismo de Peirce). Barcelona: Crítica.

Pérez, M. (2000). El Universo de la Música. Madrid: Musicalis.

Porcel, A. (2010). Lectura y Escritura Musical. Revista Digital Innovación y experiencias educativas, 37(1), 1-9. Recuperado de http:/www.csi-csif.es/andalucia/modules/mod_ ense/revista/pdf/Numero_37/ANA_MARIA_PORCEL_1.pdf

Rojas, D. (2003). La oreja en el escenario. Artes, La Revista, 5(1), 55-61.

Román, A. (2008). El lenguaje musivisual: semiótica y estética de la música cinematográfica. Madrid: Visión Libros.

Rusinek, G. (2006). ¿Qué significa saber música? Doce Notas Revista de Información Musical, 52, 16-18.

Schaeffer, P. (1996). Tratado de los objetos musicales. Madrid: Alianza Editorial.

Schultz, M. (1996). La notación musical desde la perspectiva peirciana. Revista Chilena de Semiótica, 1(1), 14-16. Recuperado de http://www.facso.uchile.c l/publicaciones/biblioteca/ docs/semiotica/semiotica1.pdf

Stubley, E. (1992). Philosophical Foundations. Handbook of researching Music. Teaching and Learning. United Kingdom: MENC Shirmer Books.

Tadeu da Silva, T. (1999). Espacios de identidad. Belo Horizonte: Autentica Editorial.

Tarasti, E. (1994). A Theory of Musical Semiotics. Bloomington: Indiana University Press.

Tobón, S. (2006). Aspectos básicos de la formación basada en competencias. TALCA, Proyecto Mesesup, 1-16. Recuperado de http://www.urosario.edu.co/CGTIC/Documentos/aspectos basicos_formacion_basada_competencias.pdf

Tobón de Castro, L. (2007). La lingüística del lenguaje: acerca de los proceso de significar y comunicar. Colombia: Universidad Pedagógica Nacional. 